\title{
Prevalence and determinants of depression in mothers of children under 5 years in Bole District, Ghana
}

\author{
Nawaf Saeed and Anthony Wemakor ${ }^{*}$ (1)
}

\begin{abstract}
Objective: Depression in mothers is a risk factor for poor health, and pregnancy and child outcomes. The objective of the present study was to determine the prevalence of depression and identify its determinants in mothers of children under 5 years in Bole District, Ghana.

Results: We conducted an analytical cross-sectional study consisting of 244 mothers (mean age $28.7 \pm 6.29$ years) in Bole District, Ghana. Edinburgh Postnatal Depression Scale was used to screen for depression and the determinants of depression were identified using logistic regression analysis. The prevalence of depression in this study population was 16.8\% (95\% confidence interval 12.1-22.0\%). The independent determinants of depression were marital status, occupation, lighting source and type of cooking fuel. Being currently unmarried ( $p<0.001)$, and using lighting sources other than electricity $(p=0.004)$ were associated with higher risk of depression while being employed in other occupations ( $p=0.001)$, and not cooking with firewood ( $p=0.008$ ) were associated with lower risk of depression. In this study population, the prevalence of depression was relatively high in mothers and was associated with marital status, occupation, lighting source and cooking fuel. Interventions to prevent and treat depression in women should include strategies to improve their socio-economic status and living conditions.
\end{abstract}

Keywords: Depression, Mothers, Firewood, Marital status, Occupation, Tamale

\section{Introduction}

Depression is common in women of childbearing age [1]. In the developed world, 10 to $16 \%$ of all mothers are estimated to experience depression [2] while in Africa, a review based on 35 studies estimated that $18.3 \%$ of mothers have depression [3]. In Northern Ghana, the prevalence of depression was estimated in two community-based studies as $27.8 \%$ in 2016 [4] and 33.5 in 2018 [5] while six studies conducted on mothers outside northern Ghana recorded lower rates (3.8-11.3\%) [6-11]. Depression is the leading cause of morbidity and mortality worldwide [12].

Maternal depression can encourage poor health behaviour and increase the risk of unfavourable birth and child

\footnotetext{
*Correspondence: anthonywemakor@yahoo.com School of Allied Health Sciences, University for Development Studies, Tamale, Ghana
}

outcomes [13]. This includes preterm birth, low birth weight, and reduced growth and psychological problems $[14,15]$. Untreated depression has been linked to the development of maladjustment in children [16] and poor psychological and physical wellbeing of children and adolescents [17].

Research in low-resourced settings has shown an association between maternal mental health and caregiving practice, and this has implications for the health and well-being of children. Studies on mothers with depressive symptoms in Ghana and Ivory Coast showed high prevalence of diarrhoeal and febrile diseases in children of depressed mothers compared to children of psychological sound mothers [11]. Additionally, maternal depression in both high- and low-income countries has been shown to negatively affect breastfeeding $[18,19]$. Some studies have found that mothers with depression stopped exclusive breastfeeding early compared to those 
without depressive symptoms and other studies found that depressive mothers were more likely to stop breastfeeding entirely in the complementary feeding period $[20,21]$.

In spite of the link between maternal mental health and pregnancy and child outcomes, data are scanty on the prevalence and determinants of depression in mothers of young children in Ghana. The objective of the present study was to determine the prevalence of depression and identify its determinants in mothers of children under 5 years in Bole District, Ghana.

\section{Main text \\ Methods \\ Study design, area and population}

An analytical cross-sectional study was conducted in Mankuma in Bole District, Ghana, in February, 2015. The Bole District is located at the extreme western part of the Savanna Region, one of the 16 administrative regions of Ghana. The study population consisted of all mothers of children under 5 years living in the Mankuma community.

\section{Sample size determination and sampling}

Using the single population proportion formula [22], a sample size of 244 was estimated. A list of all mothers of children under 5 years in the Mankuma community was compiled using Child Welfare Records with the help of community health volunteers. Simple random sampling was used in selecting the 244 mothers who were visited and interviewed at home.

\section{Data collection}

A researcher-constructed semi-structured questionnaire, and Edinburgh Postnatal Depression Scale (EPDS) were used to collect data for the study. The semi-structured questionnaire has sections on socio-demographic and economic characteristics, and household cooking fuel and lighting sources. These variables were assessed in our study because previous studies have reported their association with mental health status of women in developing countries [23-25]. The EPDS was developed for screening postpartum women in outpatient, home visit settings, or at the 6-8 weeks postpartum examination [26]. The tool has been used among numerous populations in various countries. The EPDS is made up of 10 questions. Responses are scored $0,1,2$, or 3 according to increased severity of the symptoms for questions 1,2 and 4 . Questions 3 , and 5-10 are reverse scored (i.e., 3, 2, 1, and 0). The total score is obtained by adding together the scores for each of the 10 items, which gives a maximum score of 30. The cut-off used to define depression is 12 , thus, a woman scoring 12 or more points was classified as being depressed [27]. The administration of the questionnaires was undertaken by 3 final year undergraduate students of the School of Allied Health Sciences, University for Development Studies, Tamale. The questionnaires were administered in Gonja in face-to-face interviews with the mothers.

\section{Statistical analysis}

Data were analyzed using Stata IC (Version 12.1). Means and standard deviations were calculated for continuous variables and frequencies and percentages for categorical variables. Household wealth index was derived using 12 household items i.e., radio, television, satellite dish, sewing machine, mattress, refrigerator, DVD, electric fan, mobile phone, bicycle, motorcycle and car following a standard procedure [28]. Possession of each of the items attracted a score of 1 otherwise a score of 0 . Using Principal Component Analysis, household wealth scores were derived for each household, and all the scores were ranked and divided into 3 equal groups: poorest, medium and richest. This index is considered a good proxy for socio-economic status and is routinely reported in the Ghana Demographic and Health Survey reports. Chisquare or Fisher's exact test was employed in the bivariate analyses and variables that were significant $(\mathrm{p}<0.2)$ in these analyses were considered for multivariate logistic regression analysis. Declaration of significance in the multivariate analysis was done at $\mathrm{p}<0.05$.

\section{Results}

Majority of our participants were currently married (84.0\%), belonged to the Islamic faith $(77.0 \%)$ and were from Gonja tribe (73.0\%). Most of them (43.0\%) were traders, and the majority had no education (53.3\%). Again, the majority of them had one child under 5 (70.1\%), used electricity as a source of lighting (95.5\%) and used firewood for cooking (70.5\%) (Table 1).

\section{Maternal depression and its determinants}

The prevalence of maternal depression was estimated at $16.8 \%$ (95\% confidence interval: $12.1-22.0 \%$ ) for the study subjects. In bivariate analyses, 8 variables had crude associations with depression status of the mothers namely: age $(\mathrm{p}=0.027)$, marital status $(\mathrm{p}<0.001)$, religion $(p=0.062)$, ethnicity $(p=0.058)$, occupations $(p=0.061)$, source of lighting in the house $(p<0.001)$, type of fuel used for cooking $(\mathrm{p}=0.056)$, and household wealth index $(p=0.015)$ (Table 2$)$. These variables were entered into a logistic regression model and after mutual adjustment using stepwise logistic regression procedure, marital status, occupation, source of lighting in the household, and type of fuel used for cooking remain associated with maternal 
Table 1 Socio-demographic characteristics $(n=244)$

\begin{tabular}{|c|c|c|}
\hline Characteristic & Frequency $(n)$ & Percent \\
\hline \multicolumn{3}{|l|}{ Age group (years) } \\
\hline $18-19$ & 14 & 5.7 \\
\hline $20-24$ & 48 & 19.7 \\
\hline $25-29$ & 82 & 33.6 \\
\hline $30-34$ & 58 & 23.8 \\
\hline $35-39$ & 24 & 9.8 \\
\hline $40+$ & 18 & 7.4 \\
\hline \multicolumn{3}{|l|}{ Education } \\
\hline None & 130 & 53.3 \\
\hline Primary & 55 & 22.5 \\
\hline Junior High School and above & 59 & 24.2 \\
\hline \multicolumn{3}{|l|}{ Marital status ${ }^{\mathrm{a}}$} \\
\hline Currently married & 205 & 84.0 \\
\hline Currently unmarried & 39 & 16.0 \\
\hline \multicolumn{3}{|l|}{ Religion } \\
\hline Islam & 188 & 77.0 \\
\hline Others & 56 & 23.0 \\
\hline \multicolumn{3}{|l|}{ Ethnicity } \\
\hline Gonja & 178 & 73.0 \\
\hline Others & 66 & 27.0 \\
\hline \multicolumn{3}{|l|}{ Occupation } \\
\hline Trader/vendor & 105 & 43.0 \\
\hline Housewife & 53 & 21.7 \\
\hline Others & 86 & 35.2 \\
\hline \multicolumn{3}{|c|}{ Number of children under 5 in household } \\
\hline 1 & 171 & 70.1 \\
\hline 2 & 73 & 29.9 \\
\hline \multicolumn{3}{|l|}{ Source of lighting in the house } \\
\hline Electricity & 233 & 95.5 \\
\hline Others & 11 & 4.5 \\
\hline \multicolumn{3}{|l|}{ Type of fuel used for cooking } \\
\hline Firewood & 172 & 70.5 \\
\hline Others & 72 & 29.5 \\
\hline \multicolumn{3}{|l|}{ Household wealth index (tertile) } \\
\hline Poorest & 84 & 34.4 \\
\hline Medium & 81 & 33.2 \\
\hline Richest & 79 & 32.4 \\
\hline
\end{tabular}

a Legally married women were classified as "currently married", all other women were classified as "currently unmarried"

depression independently. Being currently unmarried $(\mathrm{p}<0.001)$, and using lighting sources other than electricity $(\mathrm{p}=0.004)$ were associated with higher risk of depression while being employed in other occupations (mostly farming and provision of services) $(p=0.001)$ and not cooking with firewood $(\mathrm{p}=0.008)$ were associated with lower risk of depression (Table 3).

\section{Discussion}

The present study found the prevalence of depression to be $16.8 \%$ among mothers of children under 5 years in Mankuma in Bole District, Ghana. Among our sampled population, the independent determinants of depression are marital status, occupation, lighting source and cooking fuel.

A lower prevalence of maternal depression was estimated than previously reported for mothers in Northern Ghana. Two previous studies, both of which used the Centre for Epidemiologic Studies Depression Scale, reported about twice our rate in Northern Ghana mothers i.e., $27.8 \%$ in 2016 [4] and $33.5 \%$ in 2018 [5]. However, six studies conducted on mothers outside northern Ghana recorded lower rates $(3.8-11.3 \%)$ [6-11]. The lack of a nationally representative study on the prevalence of depression in Ghana makes judging these figures difficult. It is possible that study population, screening tool, study design and other factors explain the disparities in the rates of depression in mothers in Ghana.

We found that marital status, occupation, household lighting and cooking fuel were independently associated with depression status of the mothers. The finding of lower risk of depression for married women was supported by some studies $[29,30]$. A similar study to ours has shown that married mothers have lower chances of being depressed compared to unmarried ones especially if their husbands are literate and caring [29]. The authors attributed the higher risk of depression associated with unmarried status to lack of partners to confide in and share one's woes with and this is likely to be the situation for our study population also.

We however found a lower risk of depression for women who engaged in other occupations (mostly farming and provision of services) relative to trading. The exact reasons are not known but this may relate to the stress associated with the difficult economic situation in Ghana arising from high interest rates on bank loans [31], and the constant depreciation of the Ghanaian currency (Ghana Cedis) against the US dollar [32]. This is likely to impact traders more severely compared to people in other occupations as they need to take bank loans to run their businesses, and the US dollar is needed for importing goods. The rapid depreciation of the Ghana Cedis also means that the prices of goods keep going up and this affects sales and leads to lower return on investments.

We found an increased risk for depression for women in households not using electricity for lighting but these women were very few (4.5\% of total sample). Mothers who used other fuels were $77 \%$ less likely to be depressed compared to those who used firewood for cooking and a similar study to ours found higher rates of depression in women who used biomass for cooking compared to other 
Table 2 Comparison of depressed and non-depressed mothers $(n=244)$

\begin{tabular}{|c|c|c|c|c|}
\hline \multirow[t]{2}{*}{ Characteristic } & \multirow[t]{2}{*}{ Total } & \multicolumn{2}{|c|}{ Depression status } & \multirow[t]{2}{*}{ Test statistics } \\
\hline & & No, n (\%) & Yes, n (\%) & \\
\hline \multicolumn{5}{|l|}{ Age group (years) } \\
\hline $18-24$ & 62 & $45(72.6)$ & $17(27.4)$ & \multirow[t]{3}{*}{ Chi-square $=7.223 ; \mathrm{df}=2 ; \mathrm{p}=0.027$} \\
\hline $25-29$ & 82 & $73(89.0)$ & $9(11.0)$ & \\
\hline $30+$ & 100 & $85(85.0)$ & $15(15.0)$ & \\
\hline \multicolumn{5}{|l|}{ Education } \\
\hline None & 130 & $111(85.4)$ & $19(14.6)$ & \multirow[t]{3}{*}{ Chi-square $=1.435 ; \mathrm{df}=2 ; \mathrm{p}=0.488$} \\
\hline Primary & 55 & $43(78.2)$ & $12(21.8)$ & \\
\hline JHS and above & 59 & $49(83.1)$ & $10(16.9)$ & \\
\hline \multicolumn{5}{|l|}{ Marital status $^{\mathrm{a}}$} \\
\hline Currently married & 205 & $179(87.3)$ & $26(12.7)$ & \multirow[t]{2}{*}{ Chi-square $=15.576 ; \mathrm{df}=1 ; \mathrm{p}<0.001$} \\
\hline Currently unmarried & 39 & $24(61.5)$ & 15 (38.5) & \\
\hline \multicolumn{5}{|l|}{ Religion } \\
\hline Islam & 188 & $161(85.6)$ & $27(14.4)$ & \multirow[t]{2}{*}{ Chi-square $=3.493 ; \mathrm{df}=1 ; \mathrm{p}=0.062$} \\
\hline Others & 56 & $42(75.0)$ & $14(25.0)$ & \\
\hline \multicolumn{5}{|l|}{ Ethnicity } \\
\hline Gonja & 178 & $153(86.0)$ & $25(14.0)$ & \multirow[t]{2}{*}{ Chi-square $=3.581 ; \mathrm{df}=1 ; \mathrm{p}=0.058$} \\
\hline Others & 66 & $50(75.8)$ & $16(24.2)$ & \\
\hline \multicolumn{5}{|l|}{ Occupation } \\
\hline Trader/vendor & 105 & $82(78.1)$ & $23(21.9)$ & \multirow[t]{3}{*}{ Chi-square $=5.578 ; d f=2 ; p=0.061$} \\
\hline Housewife & 53 & $43(81.1)$ & $10(18.9)$ & \\
\hline Others $^{b}$ & 86 & $78(90.7)$ & $8(9.3)$ & \\
\hline \multicolumn{5}{|c|}{ Number of children under 5 in household } \\
\hline 1 & 171 & $140(81.9)$ & $31(18.1)$ & \multirow[t]{2}{*}{ Chi-square $=0.718 ; d f=1 ; p=0.397$} \\
\hline 2 & 73 & $63(86.3)$ & $10(13.7)$ & \\
\hline \multicolumn{5}{|c|}{ Source of lighting in the house } \\
\hline Electricity & 233 & $199(85.4)$ & $34(14.6)$ & \multirow[t]{2}{*}{$p<0.001^{c}$} \\
\hline Others & 11 & $4(36.4)$ & $7(63.6)$ & \\
\hline \multicolumn{5}{|c|}{ Type of fuel used for cooking } \\
\hline Firewood & 172 & $138(80.2)$ & $34(19.8)$ & \multirow[t]{2}{*}{ Chi-square $=3.663 ; \mathrm{df}=1 ; \mathrm{p}=0.056$} \\
\hline Others & 72 & $65(90.3)$ & $7(9.7)$ & \\
\hline \multicolumn{5}{|c|}{ Household wealth index (tertile) } \\
\hline Lowest & 84 & $62(73.8)$ & $22(26.2)$ & \multirow[t]{3}{*}{ Chi-square $=8.416 ; d f=2 ; p=0.015$} \\
\hline Medium & 81 & $70(86.4)$ & 11 (13.6) & \\
\hline Highest & 79 & 71 (89.9) & $8(10.1)$ & \\
\hline
\end{tabular}

a Legally married were classified as "currently married", all other women were classified as "currently unmarried"

b Includes agriculture workers $(n=45)$, services providers $(n=34)$ and salaried workers $(n=7)$

c Fisher's exact test used for comparison

fuels in India [24]. The use of firewood for cooking connotes underdevelopment and low socio-economic status as it is used by more than $65.0 \%$ of the population in rural areas of Ghana who are mostly poor [33] and only $5.5 \%$ of this population use liquefied petroleum gas as their main cooking fuel [34]. The mechanism by which firewood use increases the risk of depression is not known but may relate to the stress involved in gathering it from the field and the smoke associated with its use.

\section{Conclusions}

The current study found a relatively high prevalence of depression (16.8\%) in mothers of children under 5 years in Bole District, Ghana. The socio-demographic factors associated with depression were marital status, occupation, lighting source and type of cooking fuel. Interventions to prevent and treat depression in women should include strategies to improve their socio-economic status and living conditions. 
Table 3 Multivariate analysis of the determinants of depression in mothers $(n=244)$

\begin{tabular}{lll}
\hline Characteristic $\quad$ Adjusted OR & $\begin{array}{l}95 \% \\
\text { confidence } \\
\text { interval }\end{array}$ & $p$ value \\
& &
\end{tabular}

\begin{tabular}{lccc}
\hline $\begin{array}{l}\text { Marital status } \\
\text { Currently married }\end{array}$ & 1.00 & & \\
$\begin{array}{l}\text { Currently unmarried } \\
\text { Occupation }\end{array}$ & 5.24 & $2.06-13.28$ & $<0.001$ \\
$\quad$ Trader/vendor & 1.00 & & \\
Housewife & 0.38 & $0.14-1.06$ & 0.063 \\
Others & & & \\
Ethnicity & 0.18 & $0.06-0.51$ & 0.001 \\
Gonja & 1.00 & & \\
Others & 2.32 & $1.02-5.28$ & 0.046 \\
Source of lighting in the household & & \\
$\quad$ Electricity & 1.00 & & \\
Others & 8.72 & $2.00-38.08$ & 0.004 \\
Type of fuel used for cooking & & \\
Firewood & 1.00 & & \\
Others & 0.23 & $0.08-0.68$ & 0.008 \\
\hline
\end{tabular}

a Legally married women were classified as "currently married", all other women were classified as "currently unmarried"

b This includes mainly agriculture workers $(n=45)$ and services providers $(\mathrm{n}=34)$ and a few salaried workers $(\mathrm{n}=7)$

\section{Limitation}

One major limitation with our study is that, the EPDS used to determine depression status was not validated for our study population so its reliability in this context cannot be judged. Despite this limitation, this study provides significant insights into the level of depression and its determinants in mothers of children under 5 years of age in the Bole District, Ghana.

\section{Abbreviations}

AOR: adjusted odds ratio; Cl: confidence interval; EPDS: Edinburgh Postnatal Depression Scale.

\section{Acknowledgements}

We are grateful to the mothers who responded to the questionnaire.

\section{Authors' contributions}

AW conceived the study and analysed the data, NS supervised the data collection and drafted the manuscript. Both authors read and approved the final manuscript.

\section{Funding}

The study was funded by the authors.

\section{Availability of data and materials}

The minimal dataset analysed during the current study can be obtained from the corresponding author upon reasonable request.

\section{Ethics approval and consent to participate}

The study (Protocol Number 11-2014) was approved by Ethics Board of School of Medicine and Health Sciences, University for Development Studies,
Tamale. Written informed consent was obtained from the mothers before the administration of the questionnaire and screening for depression. The women were assured of anonymity and confidentiality of the study data. They were also informed that taking part in the study was voluntary and that they could withdraw at any time during the process if they felt uncomfortable.

\section{Consent for publication}

Not applicable.

\section{Competing interests}

The authors declare that they have no competing interests.

Received: 25 February 2019 Accepted: 22 June 2019

Published online: 01 July 2019

\section{References}

1. Weissman MM, Olfson M. Depression in women: implications for health care research. Science. 1995;269(5225):799-801.

2. Gotlib $॥$, et al. Prevalence rates and demographic characteristics associated with depression in pregnancy and the postpartum. J Consult Clin Psychol. 1989;57(2):269.

3. Sawyer A, Ayers S, Smith H. Pre-and postnatal psychological wellbeing in Africa: a systematic review. J Affect Disord. 2010;123(1-3):17-29.

4. Wemakor A, Mensah KA. Association between maternal depression and child stunting in Northern Ghana: a cross-sectional study. BMC Public Health. 2016;16(1):869.

5. Wemakor A, Iddrisu H. Maternal depression does not affect complementary feeding indicators or stunting status of young children (6-23 months) in Northern Ghana. BMC Res Notes. 2018;11(1):408.

6. Guo N, et al. Mental health related determinants of parenting stress among urban mothers of young children-results from a birth-cohort study in Ghana and Côte d'Ivoire. BMC psychiatry. 2014;14(1):156.

7. Okronipa HE, et al. Postnatal depression symptoms are associated with increased diarrhea among infants of HIV-positive Ghanaian mothers. AIDS Behav. 2012;16(8):2216-25.

8. Gold KJ, et al. Depression and risk factors for depression among mothers of sick infants in Kumasi, Ghana. Int J Gynecol Obstet. 2013;120(3):228-31.

9. Weobong B, et al. Determinants of postnatal depression in rural Ghana: findings from the Don population based cohort study. Depression Anxiety. 2015;32(2):108-19.

10. Weobong $\mathrm{B}$, et al. The comparative validity of screening scales for postnatal common mental disorder in Kintampo, Ghana. J Affect Disord. 2009;113(1-2):109-17.

11. Guo N, et al. Association of antepartum and postpartum depression in Ghanaian and Ivorian women with febrile illness in their offspring: a prospective birth cohort study. Am J Epidemiol. 2013;178(9):1394-402.

12. Lépine J-P, Briley M. The increasing burden of depression. Neuropsychiatr Dis Treat. 2011;7(Suppl 1):3-7.

13. Gelaye B, et al. Epidemiology of maternal depression, risk factors, and child outcomes in low-income and middle-income countries. Lancet Psychiatry. 2016;3(10):973-82.

14. Dias CC, Figueiredo B. Breastfeeding and depression: a systematic review of the literature. J Affect Disord. 2015;171:142-54.

15. Rahman A, et al. Impact of maternal depression on infant nutritional status and illness: a cohort study. Arch Gen Psychiatry. 2004;61(9):946-52.

16. Goodman SH, Garber J. Evidence-based interventions for depressed mothers and their young children. Child Dev. 2017:88(2):368-77.

17. Cruise SM, et al. Prevalence and factors associated with depression and depression-related healthcare access in mothers of 9-month-old infants in the Republic of Ireland. Epidemiol Psychiatr Sci. 2018;27(5):468-78.

18. de Jager E, et al. Psychosocial correlates of exclusive breastfeeding: a systematic review. Midwifery. 2013;29(5):506-18.

19. Ystrom E. Breastfeeding cessation and symptoms of anxiety and depression: a longitudinal cohort study. BMC Pregnancy Childbirth. 2012;12(1):36.

20. Hasselmann MH, Werneck GL, Silva CVCD. Symptoms of postpartum depression and early interruption of exclusive breastfeeding in the first two months of life. Cadernos de saude publica. 2008;24:s341-52. 
21. Rahman A, et al. The impact of perinatal depression on exclusive breastfeeding: a cohort study. Matern Child Nutr. 2016;12(3):452-62.

22. Snedecor GW, Cochran GW. Statistical methods. Ames: Iowa State University Press; 1989.

23. Fisher J, et al. Prevalence and determinants of common perinatal mental disorders in women in low-and lower-middle-income countries: a systematic review. Bull World Health Organ. 2012;90:139-49.

24. Banerjee $M$, et al. Cooking with biomass increases the risk of depression in pre-menopausal women in India. Soc Sci Med. 2012;75(3):565-72.

25. Ayano G, Tesfaw G, Shumet S. Prevalence and determinants of antenatal depression in Ethiopia: a systematic review and meta-analysis. PLoS ONE. 2019;14(2):e0211764.

26. Cox JL, Holden JM, Sagovsky R. Detection of postnatal depression: development of the 10-item Edinburgh Postnatal Depression Scale. Br J Psychiatry. 1987;150(6):782-6.

27. Eberhard-Gran $M$, et al. Review of validation studies of the Edinburgh Postnatal Depression Scale. Acta Psychiatr Scand. 2001;104(4):243-9.

28. Garenne M, Hohmann-Garenne S. A wealth index to screen high-risk families: application to Morocco. J Health Popul Nutr. 2003;21:235-42.

29. Okewole AO, et al. Maternal depression and child psychopathology among Attendees at a Child Neuropsychiatric Clinic in Abeokuta,
Nigeria: a cross sectional study. Child Adolesc Psychiatry Mental Health. 2016;10(1):30.

30. Maharaj RG. Depression and the nature of Trinidadian family practice: a cross-sectional study. BMC Family Pract. 2007;8(1):25.

31. Kwakye JK. High interest rates in Ghana, a critical analysis. Accra: IEA Ghana; 2010.

32. Alagidede P, Ibrahim M. On the causes and effects of exchange rate volatility on economic growth: evidence from Ghana. J Afr Bus. 2017;18(2):169-93.

33. GSS, GHS and ICF International. Ghana demographic and health survey 2014. Rockville: GSS, GHS, and ICF International; 2015.

34. Ghana Statistical Service. Ghana living standards survey round 6 (GLSS6). Accra: Ghana Statisical Service; 2014.

\section{Publisher's Note}

Springer Nature remains neutral with regard to jurisdictional claims in published maps and institutional affiliations.
Ready to submit your research? Choose BMC and benefit from:

- fast, convenient online submission

- thorough peer review by experienced researchers in your field

- rapid publication on acceptance

- support for research data, including large and complex data types

- gold Open Access which fosters wider collaboration and increased citations

- maximum visibility for your research: over $100 \mathrm{M}$ website views per year

At BMC, research is always in progress.

Learn more biomedcentral.com/submissions 